\title{
Organização das Comunidades Infestantes de Plantas Daninhas na Cultura da Cana-de-AçúCar em Agrupamentos-Padrão ${ }^{1}$
}

\author{
Organization of Weed Communities in Sugarcane Standard Groupings
}

\author{
FERREIRA, R.V. ${ }^{2}$, CONTATO, E.D. ${ }^{3}$, KUVA, M.A. ${ }^{3}$, FERRAUDO, A.S. ${ }^{4}$, ALVES, P.L.C.A. ${ }^{4}$, \\ MAGARIO, F.B. ${ }^{5}$ e SALGADO, T.P. ${ }^{3}$
}

\begin{abstract}
RESUMO - O objetivo deste estudo foi avaliar a possibilidade de agrupar talhões de cana-deaçúcar colhida mecanicamente e sem queima prévia da palha na região de Ribeirão Preto-SP, de acordo com o potencial de infestação de plantas daninhas, por meio de análise de agrupamento por método hierárquico e outras técnicas de análise multivariada, utilizando como variável o indice de infestação relativa atribuído por avaliações visuais, em duas etapas. A primeira contemplou 20 talhões de cana-planta com ciclo de 18 meses; essas áreas foram utilizadas para comparação de dois métodos de estimativa da composição específica da flora daninha: análise fitossociológica e por meio da porcentagem visual de cobertura geral (CG) e especifica (CE). A segunda etapa consistiu no levantamento da composição específica da comunidade de plantas daninhas em 189 talhões, em áreas de cana-soca colhidas durante a safra de 2008, incluindo nesses talhões apenas CG e CE. Com as informações sobre os levantamentos da comunidade infestante foi construido um banco de dados, posteriormente submetido a análises exploratórias por técnicas de estatística multivariada. Para as principais espécies dentro dos talhões, que foram DIGNU, ARACH, IPOHF, MRRCI e IPOQU, seguidas de CYPRO, ELEIN e EPHHS, foram verificados $75 \%$ de coincidências de resultados entre os dois métodos de avaliação. Também notou-se que as avaliações visuais de porcentagem de cobertura das espécies podem substituir, para fins de praticidade, agilidade e aplicabilidade, as avaliações fitossociológicas, uma vez que proporcionaram boa capacidade de detecção das principais plantas daninhas dentro de cada talhão. As técnicas de estatística multivariada demonstraram que os talhões podem ser agrupados de acordo com semelhanças na intensidade da infestação e na composição específica.
\end{abstract}

Palavras-chave: análise multivariada, cana crua, fitossociologia, matologia, Saccharum spp.

\begin{abstract}
The aim of this study was to evaluate the possibility of grouping stands of sugarcane harvested mechanically, and without previous straw burning in the region of Ribeirão Preto-SP, according to the potential of weed infestation. Clustering analysis and other multivariate analysis techniques were applied, using as variable the relative rate of infestation assigned by visual assessments, in two phases: in the first, twenty sugarcane plots with an 18-month cycle were selected. These areas were used to compare two methods to estimate the specific composition of the weeds, namely, a phytosociological analysis, described by Mueller-Dombois \& Ellenberg (1974) and an analysis of the visual percentage of general coverage (GC) and specific coverage (SC). In the second phase, the specific composition of the weed community was evaluated in 189 plots in areas of ratoon sugarcane harvested in 2008, attributing to these plots only GC and SC. Based on the information obtained on the weed community, a database was built, and subjected to exploratory analysis of multivariate statistical techniques. For the main species within the stands (DIGNU, ARACH, IPOHF, MRRCI and IPOQU, followed by CYPRO, ELEIN and EPHHS), 75\% of coinciding results were verified between the two methods. It was found that the visual assessments of species coverage percentage may substitute, for purposes of convenience, flexibility and applicability, the
\end{abstract}

Recebido para publicação em 22.10.2010 e na forma revisada em 6.5.2011.

2 Engo-Agr ${ }^{-}$., Mestre em Agronomia (Produção Vegetal), Faculdade de Ciências Agrárias e Veterinárias, Universidade Estadual Paulisa "Júlio de Mesquita Filho" - FCAV/UNESP; ${ }^{3}$ Herbae Consultoria e Projetos Agrícolas Ltda.; ${ }^{4}$ Professor Dr., Dep. de Biologia Aplicada à Agropecuária, FCAV/UNESP, Via de acesso Prof. Paulo Donato Castellane, s/n, 14884-900, $<$ plalves@fcav.unesp.br>; ${ }^{5}$ Graduando em Agronomia, FCAV/UNESP.

Planta Daninha, Viçosa-MG, v. 29, n. 2, p. 363-371, 2011 
phytosociological evaluations, as these assessments provided good detection capability of the main weeds in each stand. The techniques of multivariate statistics showed that the plots can be grouped according to similarities in infestation intensity and species composition.

Keywords: multivariate analysis, ratoon sugarcane, phytosociological study, weed survey, Saccharum spp.

\section{INTRODUÇÃO}

As plantas daninhas estão entre os principais componentes do agroecossistema da cana-de-açúcar, já que a presença dessas plantas pode afetar o processo produtivo da cultura, competindo pelos recursos do meio, hospedando pragas e doenças ou interferindo nas práticas culturais e na colheita (Pitelli, 1985). O potencial de redução de produtividade é variável e depende da severidade de infestação e das principais espécies presentes. Resultados de pesquisa indicaram que em uma área onde predominava tiririca a produtividade foi reduzida em $20 \%$ (Kuva et al., 2000); em infestação predominantemente de capim-braquiária ocorreram perdas de até $82 \%$ (Kuva et al., 2001); em infestação mista de capim-braquiária e capim-colonião as perdas foram de 40\% (Kuva et al., 2003); em infestação mista de capim-colonião e folhas largas as perdas alcançaram 33\% (Meirelles et al., 2009); e em infestação predominantemente de corda-de-viola houve redução de 46\% (Silva et al., 2009). As operações relacionadas ao controle de plantas daninhas demandam de $30 \%$ a $35 \%$ (cana-planta) e de $40 \%$ a $45 \%$ (canasoca) dos recursos empregados no cultivo da cana-de-açúcar (Rolim \& Pastre, 2000).

A aplicação de herbicidas, empregados em aproximadamente $90 \%$ das áreas, é o método de controle mais utilizado para minimizar a interferência negativa das plantas daninhas na cana-de-açúcar (Kissmann, 2000). Para melhor utilização desses produtos, o conhecimento das características dos herbicidas, das condições do ambiente e da composição específica da comunidade infestante é ponto relevante. Nesse contexto, o estudo mais aprofundado da composição de plantas daninhas poderá contribuir para redução de despesas destinadas ao controle, pois os recursos poderão ser empregados de maneira mais criteriosa e específica, em função do detalhamento das características da área e sua organização em talhões ou unidades de colheita, agrupando aqueles com nível mínimo de similaridade, considerando os indices relevantes e práticos, os quais poderão ser úteis na tomada de decisões relativas aos tratamentos químicos destinados ao controle de plantas daninhas (Kuva et al., 2006). Para esse tipo de trabalho, a análise multivariada já tem sido utilizada como ferramenta no estudo do comportamento de colonização de macrófitas aquáticas (Pitelli et al., 2009) e para diferenciar espécies de plantas daninhas de um mesmo gênero ou de gêneros distintos (Costa et al., 2006).

Um procedimento adotado por algumas usinas é a chamada matologia, que constitui na manutenção e no monitoramento de áreas de observação dentro dos talhões sem aplicação de herbicidas. Essa prática tem permitido aos responsáveis pelo controle de plantas daninhas conhecer melhor o potencial de infestação dos talhões, bem como obter informações sobre a real contribuição dos tratamentos químicos com herbicidas que foram aplicados no restante do talhão. Em alguns casos, o banco de dados engloba inúmeras informações, o que requer o uso de técnicas de estatística para obter as mais relevantes.

Esta pesquisa teve por objetivo avaliar a possibilidade de agrupar talhões de cana-deaçúcar colhida mecanicamente e sem queima prévia da palha na região de Ribeirão PretoSP, de acordo com o potencial de infestação de plantas daninhas, por meio de análise de agrupamento por método hierárquico e outras técnicas de análise multivariada, utilizando como variável o índice de infestação relativa atribuído por avaliações visuais.

\section{MATERIAL E MÉTODOS}

Esta pesquisa foi composta por duas etapas, ambas realizadas em unidade produtora de cana-de-açúcar na região de Ribeirão PretoSP. Na primeira. foram efetuadas amostragens 
em 20 talhões para conhecer a composição florística da comunidade infestante, atribuindo-se visualmente notas de porcentagem de cobertura geral (CG) e cobertura específica $(\mathrm{CE})$ em áreas amostrais (matologia) com dimensão de 12,0 x 7,5 m. Essas áreas foram locadas nos talhões, respeitando-se a distância mínima de $30 \mathrm{~m}$ em relação ao carreador mais próximo. Posteriormente, na mesma área de matologia, um quadro amostral de $0,50 \times 0,50 \mathrm{~m}\left(0,25 \mathrm{~m}^{2}\right)$ foi arremessado por 10 vezes, sendo as espécies de plantas daninhas identificadas, coletadas e contadas. Posteriormente, foram postas para secar em estufa de circulação forçada de ar a $70{ }^{\circ} \mathrm{C}$, por $96 \mathrm{~h}$, para determinação da massa seca.

Os dados de número de plantas, massa seca e frequência específica foram utilizados para determinação dos índices fitossociológicos: densidade relativa - De; dominância relativa - Do; frequência relativa - Fr.R; e indice de valor de importância - IVI, conforme metodologia de Mueller-Dombois \& Ellemberg (1974).

A cobertura geral (CG) foi caracterizada com nota crescente, variando entre 0 e $100 \%$ de acordo com a infestação, considerando todas as espécies. O mesmo critério foi adotado para caracterizar a cobertura especifica $(\mathrm{CE})$, aplicando-se notas para cada espécie encontrada.

Para minimizar os desvios entre as porcentagens de cobertura ( $\mathrm{CG}$ e $\mathrm{CE}$ ), foi calculado o indice de infestação relativa (I.I.R.) segundo a fórmula:

$$
\text { I.I.R.\% }=(\mathrm{CECG}) / 100
$$

Na segunda etapa do trabalho foram amostrados 189 talhões em áreas de matologia que ficaram livres da aplicação comercial de herbicidas, determinando-se apenas a CG e CE.

Previamente à realização das análises estatísticas, reduziu-se o número de categorias para plantas daninhas, adotando como critério o nível de participação mínima da composição específica nos talhões estudados na segunda etapa. Assim, os 48 táxons encontrados nos levantamentos foram reduzidos a nove categorias: DIGSS, BRAPL, AMASS, EPHHS, CYNDA, EPHHL, CLEAF, CYPRO, CORDA e OUTRAS. As categorias DIGSS e
AMASS contemplam todas as espécies encontradas do complexo capim-colchão e caruru, respectivamente. As categorias BRAPL, EPHHS, CYNDA e EPHHL contemplam as espécies Brachiaria plantaginea, Chamaesyce hissopifolia, Cynodon dactylon e Euphorbia heterophylla, respectivamente. Na categoria CORDA encontram-se as espécies I. quamoclit, I. grandifolia, I. nil, I. hederifoia, I. purpurea e $M$. aegyptia; a categoria OUTRAS contempla todas as espécies que não atingiram $2 \%$ de participação, considerando todas as unidades que compõem a pesquisa e que no contexto geral apresentaram pouca importância individualmente. De acordo com a porcentagem de cobertura, essas categorias foram agrupadas em alta, média ou baixa infestação.

Com os dados obtidos, foi elaborada uma ordenação das principais espécies dentro dos talhões amostrados, adotando como critério o indice de valor de importância (IVI) ou a porcentagem de cobertura das espécies, determinando-se, ao final, a porcentagem de coincidências de posições na ordenação.

O banco de dados obtido foi submetido a análises exploratórias por meio de técnicas de estatística multivariada de dados. Foi realizada a análise de agrupamento hierárquico (Hair Jr. et al., 2005), buscando organizar as comunidades de plantas em grupos, segundo seus padrões de composição, utilizando a distância euclidiana como medida de semelhança entre os talhões e, como estratégia de agrupamento, o método UPGMA (Unweighted Pair-Group Method using Arithmetic Averages). Para esta análise foram excluídos talhões cuja área de amostragem da composição florística não apresentou nenhuma planta daninha, pois foram diretamente classificados em um grupo específico. Os dados também foram submetidos à análise discriminante, segundo metodologia recomendada por Tabachnick \& Fidell (1983) e Engelman (1997).

\section{RESULTADOS E DISCUSSÃO}

Na Tabela 1 encontram-se as três principais espécies de plantas daninhas nos 20 talhões de cana-planta, de acordo com a participação na comunidade infestante, ordenadas por dois critérios: fitossociológico (IVI) e visual (IIR). Para as espécies DIGNU, 
Tabela 1 - Relação das três principais espécies de plantas daninhas nos 20 talhões de cana-planta, de acordo com a participação na comunidade infestante, ordenadas por dois critérios: fitossociológico (IVI) e visual (IIR)

\begin{tabular}{|c|c|c|c|c|c|c|}
\hline \multirow{2}{*}{ Talhão } & \multicolumn{2}{|c|}{ Primeira } & \multicolumn{2}{|c|}{ Segunda } & \multicolumn{2}{|c|}{ Terceira } \\
\hline & IVI & IIR $\%$ & IVI & IIR $\%$ & IVI & IIR $\%$ \\
\hline 1 & DIGNU & CYPRO & CYPRO & DIGNU & EPHHS & $\begin{array}{l}\text { EPHHS } \\
\text { AMASS }\end{array}$ \\
\hline 2 & CYPRO & CYPRO & IPOHF & IPOHF & ELEIN & \\
\hline 3 & IPOHF & IPOHF & DIGNU & $\begin{array}{c}\text { DIGNU } \\
\text { EPHHS } \\
\text { IPOQU } \\
\text { SIDSS }\end{array}$ & BOILF & \\
\hline 4 & DIGNU & DIGNU & EMISO & BRADC & RHYRE & \\
\hline 5 & DIGNU & DIGNU & ELEIN & $\begin{array}{c}\text { ELEIN } \\
\text { AMASS }\end{array}$ & AMASS & \\
\hline 6 & DIGNU & DIGNU & CCHEC & CYPRO & SORAR & $\begin{array}{l}\text { CCHEC } \\
\text { BRAPL }\end{array}$ \\
\hline 7 & ARACH & ARACH & DIGNU & DIGNU & EPHHL & $\begin{array}{c}\text { EPHHL } \\
\text { ELEIN } \\
\text { EPHHS }\end{array}$ \\
\hline 8 & ARACH & ARACH & BIDPI & $\begin{array}{c}\text { BIDPI } \\
\text { DIGNU }\end{array}$ & DIGNU & $\begin{array}{c}\text { ELEIN } \\
\text { AMASS } \\
\text { EPHHI }\end{array}$ \\
\hline 9 & IPOHF & MRRCI & MRRCI & $\begin{array}{l}\text { IPOQU } \\
\text { IPOHF }\end{array}$ & & \\
\hline 10 & MRRCI & MRRCI & IPOHF & IPOHF & IPOQU & $\begin{array}{l}\text { IPOQU } \\
\text { DIGNU }\end{array}$ \\
\hline 11 & ARACH & ARACH & IPOHF & IPOHF & DIGNU & DIGNU \\
\hline 12 & ELEIN & IPOHF & DIGNU & DIGNU & AMASS & ELEIN \\
\hline 13 & POROL & POROL & IPOHF & IPOHF & EPHHL & $\begin{array}{l}\text { EPHHL } \\
\text { DIGNU }\end{array}$ \\
\hline 14 & SIDSS & SIDSS & CYPRO & BRADC & BRADC & CYPRO \\
\hline 15 & CYPRO & CYPRO & CYPRO & IPOHF & IPOHF & SIDSS \\
\hline 16 & EMISO & MRRCI & DIGNU & $\begin{array}{c}\text { EPHHS } \\
\text { EMISO } \\
\text { IPOHF } \\
\text { SIDSS }\end{array}$ & MRRCI & $\begin{array}{l}\text { DIGNU } \\
\text { CASOB }\end{array}$ \\
\hline 17 & DIGNU & MRRCI & ELEIN & DIGNU & EPHHS & $\begin{array}{l}\text { EPHHS } \\
\text { PHBPU }\end{array}$ \\
\hline 18 & MRRCI & MRRCI & PHBPU & $\begin{array}{l}\text { PHBPU } \\
\text { DIGNU }\end{array}$ & IPOQU & IPOQU \\
\hline 19 & DIGNU & DIGNU & CASOB & CASOB & MRRCI & MRRCI \\
\hline 20 & ARACH & ARACH & AMASS & AMASS & ELEIN & $\begin{array}{r}\text { ELEIN } \\
\text { PANMA }\end{array}$ \\
\hline $\mathrm{PC}^{1 /}$ & & & & & & \\
\hline
\end{tabular}

1/ Porcentagem de coincidências. 
ARACH (amendoim), IPOHF, MRRCI e IPOQU, seguidas de CYPRO, ELEIN e EPHHS, foram verificados $75 \%$ de coincidências de resultados entre os dois métodos de avaliação, destacando-se as espécies DIGNU, ARACH, MRRCI CYPRO e IPOHF; na segunda comparação houve $60 \%$ de coincidência, destacando-se IPOHF, DIGNU, CASOB e AMASS. Embora as duas últimas espécies não representem as principais infestantes da cultura da cana-deaçúcar, suas características e ciclos reprodutivos as tornam importantes em áreas de instalação da cultura canavieira onde houve, por muito tempo, a exploração de pastagem. Para a terceira comparação, a coincidência foi de $45 \%$, destacando-se a ocorrência múltipla de espécies no levantamento visual: EPHHS+ AMASS, IPOQU+DIGNU e DIGNU+EPHHL, além de IPOQU e MRRCI. Nos casos em que não houve coincidência de espécie na primeira posição, a espécie detectada como a principal, utilizando o índice de valor de importância (IVI), esteve sempre presente entre as principais, seja em segundo lugar, nos talhões 1 , 9, 16 e 17, ou, na pior das hipóteses, em terceiro, no talhão 12. Além disso, verificou-se que algumas espécies não detectadas pelo método fitossociológico o foram pelas avaliações visuais. O conjunto desses resultados indica que, para fins de praticidade, agilidade e aplicabilidade, os levantamentos fitossociológicos pelo método dos quadrados de amostragem podem ser substituídos pelas avaliações visuais por meio de atribuições de porcentagens de cobertura, desde que realizadas por técnicos treinados. Quanto maior o número de pontos amostrados a cada 50 hectares (ha), variando a padronização das unidades de produção, será possivel chegar, a médio ou longo prazo, a um perfil que melhor elucida o conhecimento das espécies envolvidas no sistema, seja para cana-planta ou para cana-soca colhida mecanicamente e sem a queima prévia da palha.

Os estudos da composição florística realizados na unidade de produção podem contribuir para melhor alocar os recursos para controle de plantas daninhas, por permitirem o conhecimento da infestação e o monitoramento de resultados obtidos. No entanto, os custos e a operacionalização desse processo devem ser baixos o suficiente para viabilizar essa implantação.
Preliminarmente, na realização da análise de agrupamento hierárquico, foi isolado um grande grupo formado por 70 talhões, no qual nenhuma planta foi detectada nas áreas de levantamento da composição florística, sendo, portanto, considerado de muito baixa infestação e denominado de padrão MB. Os resultados da análise de agrupamento hierárquico realizada nos 119 talhões restantes (Figura 1), utilizando os indices de infestação relativa (I.I.R) das diferentes categorias (espécies ou grupo de espécies), indicaram a presença de dois grandes grupos: o primeiro, denominado de G1, composto por talhões com os maiores IIR, e o segundo, denominado de G2, abrangendo os talhões com os menores IIR. Todavia, considerando critérios relevantes ao controle químico, foram identificados vários subgrupos, resultando em mais 10 padrões de infestação, como pode ser observado nas Figuras 2 e 3. Os padrões foram identificados como: Acyn, caracterizado pela alta infestação com predomínio absoluto de Cynodon dactylon; Aeph, pela alta infestação com predomínio de Euphorbia heterophylla; Amis, pela alta infestação mista; Acor, pela alta infestação com predomínio de espécies de corda-de-viola; AcorMmis, pela alta infestação de espécies de corda-de-viola, mas com média presença de outras espécies; Mcor, pela média presença de espécies de corda-de-viola em presença marcante de outras espécies; Mmis, por baixa infestação mista; Bcor, pela predominância de plantas de cordade-viola, porém em baixa infestação; Beph, pela predominância de Euphorbia heterophylla, mas em baixa infestação; e Bmis, por infestação mista em baixa densidade.

No padrão Acyn encaixaram-se cinco talhões. Cynodon dactylon é considerada uma das plantas daninhas de maior dificuldade de controle na cana-de-açúcar, uma vez que medidas isoladas de controle químico são consideradas pouco efetivas; por isso, há necessidade de se utilizar um programa de controle integrando, com medidas mecânicas e químicas por ocasião da renovação do canavial, até aplicações em jato dirigido em canaviais recém-implantados. Segundo Kissmann (1997), essa planta daninha está em diversas culturas, dentre as quais se destaca a canade-açúcar; uma alta infestação pode reduzir em até $80 \%$ a produção, além de diminuir o 


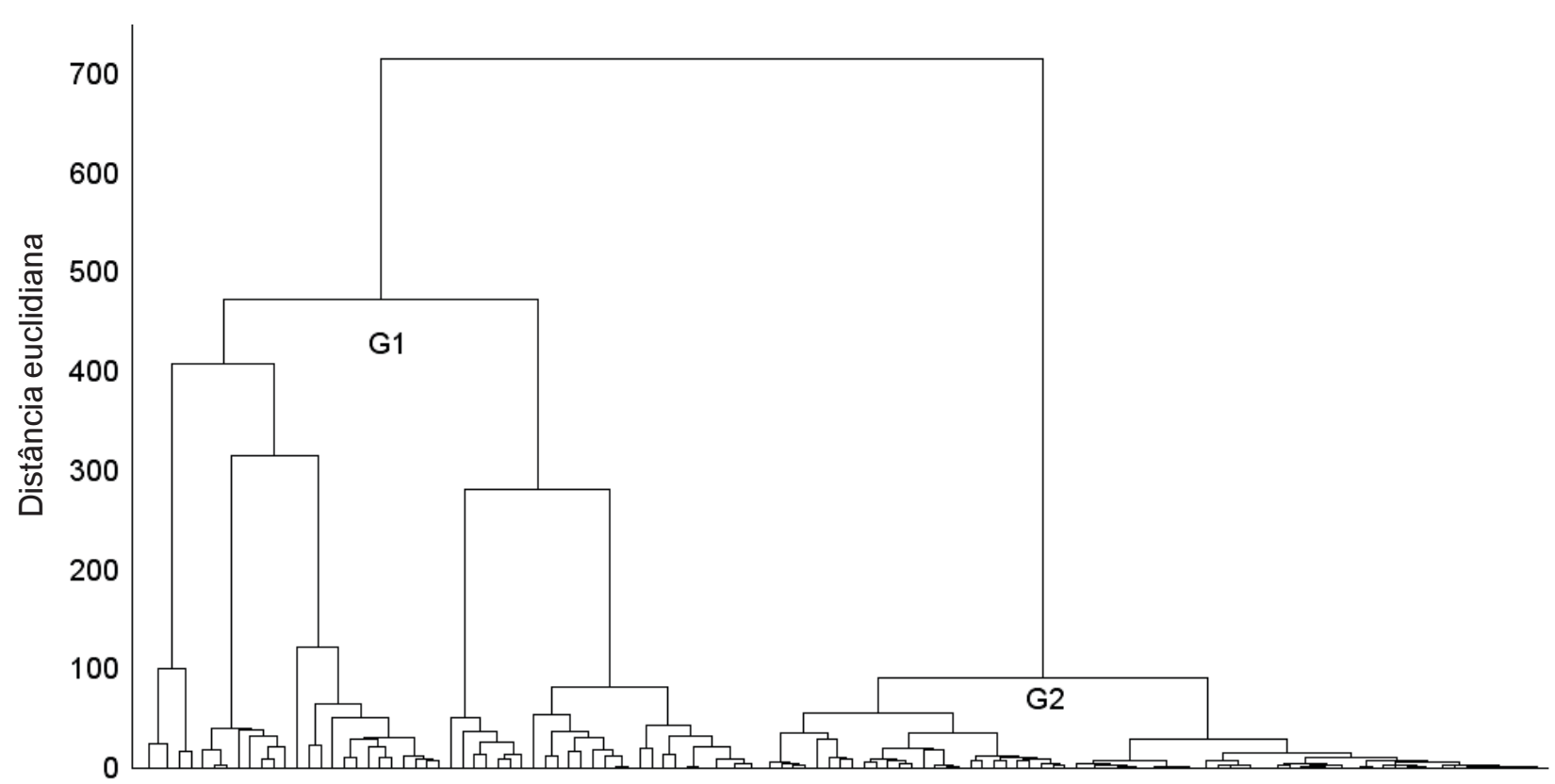

Figura 1 - Dendrograma resultante da análise de agrupamento realizado com os índices de infestação relativa (I.I.R) das diferentes espécies ou conjunto de espécies de planta daninha.

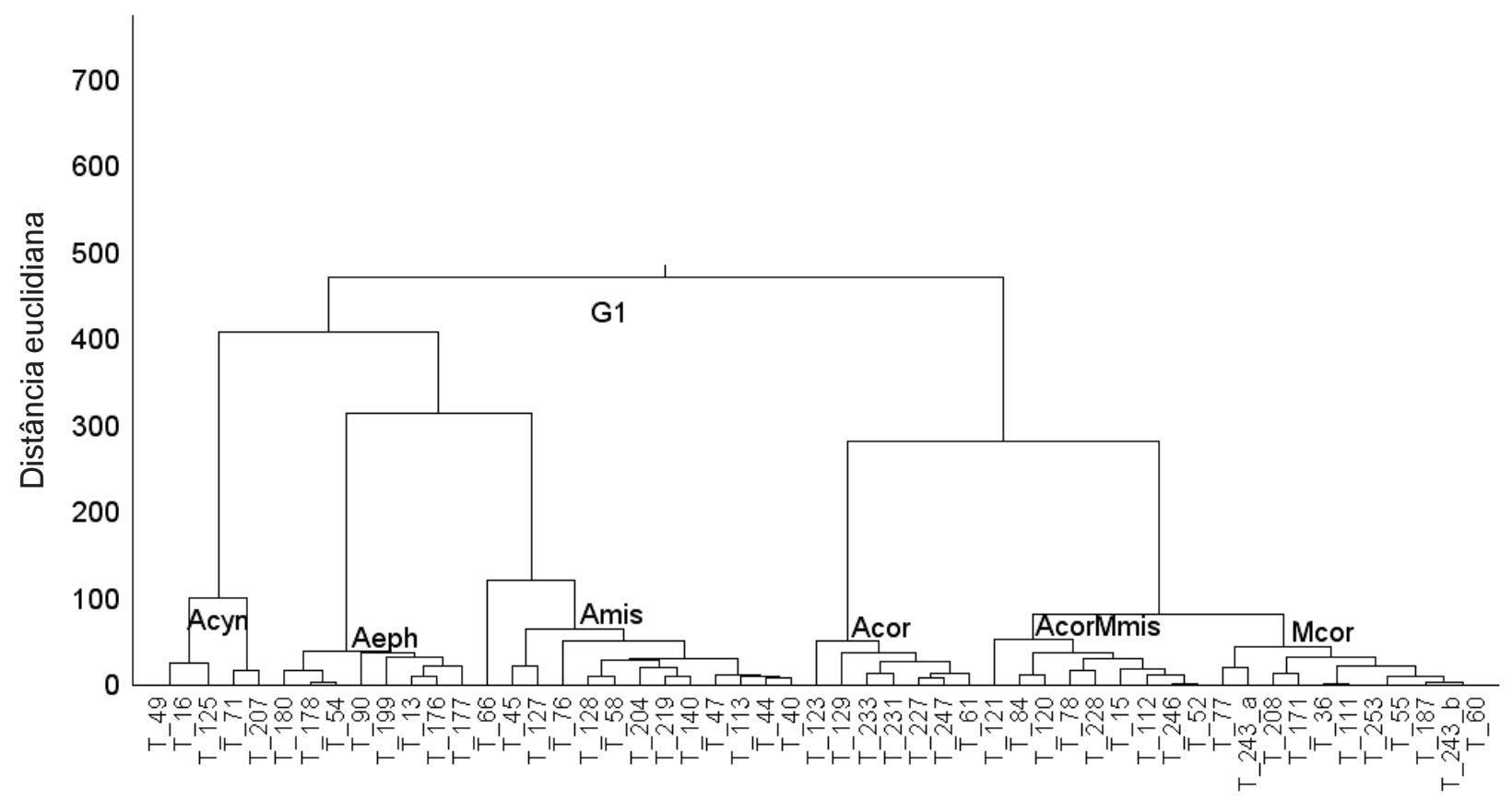

Figura 2 - Detalhamento do primeiro grupo (G1) do dendrograma resultante da análise de agrupamento realizado com os índices de infestação relativa (I.I.R) das diferentes espécies ou conjunto de espécies de planta daninha.

número de cortes e a vida útil do canavial. O uso de herbicidas tem sido restrito ao período de reforma do canavial, pois nessa fase são utilizados herbicidas não seletivos.
No padrão Aeph encaixaram-se oito ta1hões. Euphorbia heterophylla sempre esteve mais associada às culturas de grãos, principalmente à da soja. Por apresentarem sementes 


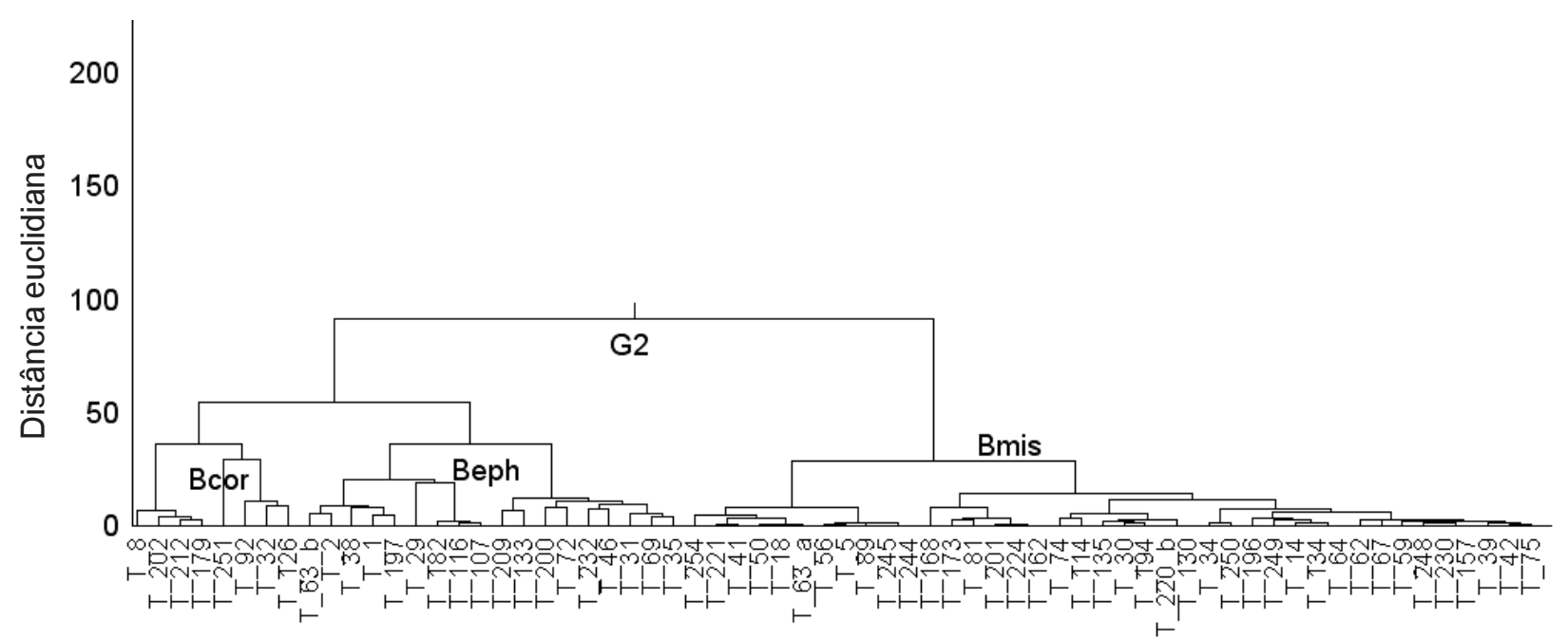

Figura 3 - Detalhamento do segundo grupo (G2) do dendrograma resultante da análise de agrupamento realizado com os índices de infestação relativa (I.I.R) das diferentes espécies ou conjunto de espécies de planta daninha.

de tamanho relativamente grande e com boa quantidade de reserva, suas plântulas têm conseguido ultrapassar a camada de palha e se estabelecer nos canaviais. Estudos realizados por Martins et al. (1999) e Gravena et al. (2004) já indicavam que essa espécie poderia ter sua importância aumentada na cultura da cana-de-açúcar pelo fato de suas plântulas emergirem sob a palha, por não dependerem da luz (Salvador et al., 2007) e pelo fato de a palha interferir negativamente na eficácia dos herbicidas utilizados para seu controle (Monquero et al., 2007). Em razão de suas populações atingirem altas densidades, apesar de apresentar ciclo anual com pequeno acúmulo de massa quando comparado ao de outras espécies, como as dos gêneros Ipomoea e Merremia, ela merece maior atenção.

Os padrões Acor, AcorMmis e Mcor foram representados pelos talhões 7,9 e 11 , respectivamente. As cordas-de-viola têm se destacado nas áreas de cana-de-açúcar com histórico de colheita mecanizada sem queima prévia da palhada. Estudos fitossociológicos realizados por Kuva et al. (2007) em áreas antigas de cana crua indicaram que, em uma escala de importância relativa, quatro espécies desse grupo se destacaram entre as 15 principais: Ipomoea hederifolia (2), I. nil (3으, I. quamoclit (7을 $\mathrm{e}$ Merremia cissoides (15).

Esse cenário já era esperado, pois, segundo estudos realizados por Martins et al. (1999),
Azania et al. (2002) e Gravena et al. (2004), as sementes de corda-de-viola apresentam grande quantidade de reserva, possibilitando a emergência das plântulas sob camadas com quantidades variáveis de palha. O desenvolvimento das plantas ocorre mesmo na fase de maior crescimento dos canaviais; as plantas adultas se entrelaçam aos colmos e folhas, interferindo negativamente no desenvolvimento da planta, nas práticas culturais e na colheita (Azania et al., 2002). Por ocasião da colheita, seus frutos e suas sementes podem estar ainda ligados à planta-mãe, favorecendo a disseminação pela colhedora para médias e longas distâncias.

Em campo, Silva et al. (2009) constataram que uma comunidade de plantas daninhas com predominio de $I$. hederifolia pode conviver por 33 dias com a cana-de-açúcar a partir do cultivo. Segundo esses autores, o potencial total de redução de produtividade da cana pela interferência dessa comunidade de plantas daninhas foi de $46 \%$, além da interferência indireta pela dificuldade da colheita.

Os padrões Amis e Mmis foram representados por 13 e 26 talhões, respectivamente. Neles estão contidas várias espécies de plantas daninhas, algumas que predominavam nos sistema de colheita mecanizada e que estão em declínio populacional ou se adaptando ao novo ambiente, como Digitaria spp., Brachiaria plantaginea e $B$. decumbens, além de outras 
que podem estar sendo beneficiadas pelo novo sistema de colheita e que estão aumentando suas populações com diferentes ritmos de crescimento, como Cleome affinis, Ricinus communis, Luffa aegyptiaca, Momordica charantia, entre outras (Kuva et al., 2008). Esse ritmo de crescimento dependerá da eficiência do mecanismo de dispersão e das estratégias de controle.

Nos padrões MB, Bcor, Beph e Bmis, ajustaram-se 70, 11, 6 e 14 talhões, o que correspondeu a $53,4 \%$ destes. Para esse grupo, mesmo com a baixa representatividade amostral das espécies, vale destacar a possibilidade de se estabelecer um programa de monitoramento e destinar uma parte desses talhões para tratar com produtos de ação pós-emergente, respeitando a capacidade operacional da usina, ou mesmo empregar tratamentos menos onerosos.

Considerando os 119 talhões nos quais pelo menos uma espécie de planta daninha foi encontrada nos levantamentos de flora e analisando os dados pela análise discriminante (Figura 4), verificou-se que, para a maioria das situações de alta infestação, a separação dos grupos de talhões foi bastante nítida. Por outro lado, para as situações de alta infestação mista, média e baixa infestação, não foi possivel separar de forma clara os grupos. De certa forma, essa análise discriminante confirma, em parte, os resultados obtidos na análise de agrupamento. Na estratégia de manejo de plantas daninhas em uma unidade produtiva, as maiores atenções devem estar voltadas para os grupos mais isolados, que se caracterizaram pela alta infestação por determinada espécie ou grupo de espécies. A adoção de estratégias de controle específico para cada um desses grupos poderá contribuir para deslocar, ao longo do tempo, os talhões para outros grupos cuja infestação de plantas daninhas é menor.

Concluiu-se que as avaliações visuais de porcentagem de cobertura das espécies podem substituir, para fins de praticidade, agilidade e aplicabilidade, as avaliações fitossociológicas, já que proporcionaram boa capacidade de detecção das principais plantas daninhas dentro de cada talhão. As técnicas de estatística multivariada, agrupamento hierárquico e análise discriminante demonstraram que os talhões podem ser agrupados de acordo com

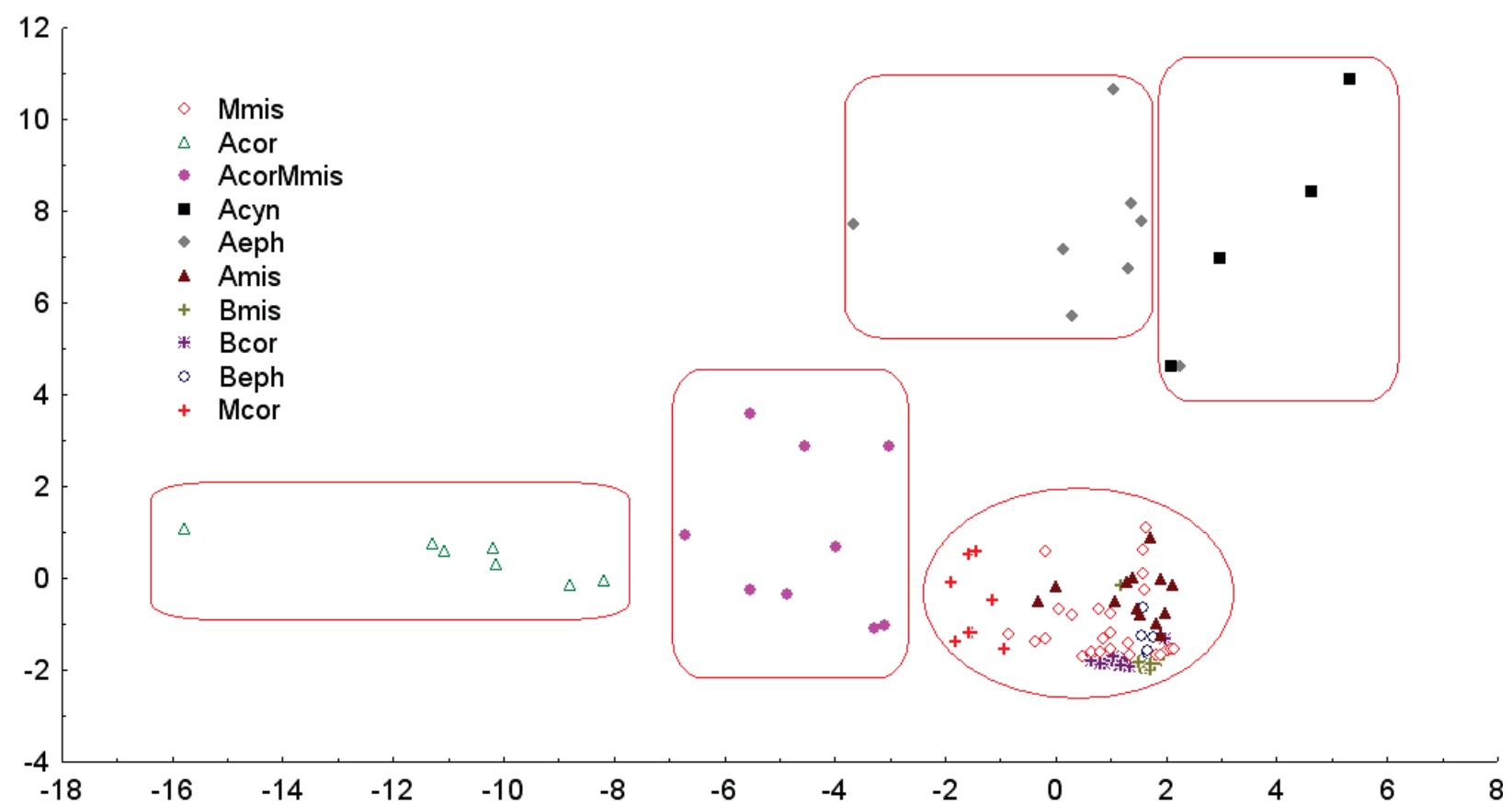

Figura 4 - Distribuição gráfica da análise discriminante de 119 talhões de cana-soca, de acordo com suas composições específicas de plantas daninhas. 
semelhanças na intensidade da infestação e composição específica, sendo segregados 10 padrões de infestação.

\section{LITERATURA CITADA}

AZANIA, A. A. P. M. et al. Interferência da palha de canade-açúcar (Saccharum spp.) na emergência de espécies de plantas daninhas da família Convolvulaceae.

Planta Daninha, v. 20, n. 2, p. 207-212, 2002.

COSTA, N. V.; RODELLA, R. A.; MARTINS, D.

Diferenciação de espécies daninhas aquáticas pela análise multivariada de caracteres estruturais foliares.

Planta Daninha, v. 24, n. 4, p. 13-20, 2006.

ENGELMAN, L. Discriminant analysis. In: WILKINSON, L. (Ed.). SYSTAT 7.0 Statistics. Chicago: 1997. 751 p.

GRAVENA, R. et al. Controle de plantas daninhas através da palha de cana-de-açúcar associada à mistura dos herbicidas trifloxysulfuron sodium + ametrina. Planta Daninha, v. 22, n. 2, p. 419-427, 2004.

HAIR JR., J. F. et al. Análise multivariada de dados. 5.ed. Porto Alegre: Bookman, 2006. 593 p.

KISSMANN, K. G. Uso de herbicidas no contexto do mercosul. In: CONGRESSO BRASILEIRO DA CIÊNCIA DAS PLANTAS DANINHAS, 22., 2000, Foz do Iguaçu, 2000. Livro de palestras... Foz do Iguaçu: 2000. p. 92-116.

KISSMANN, K. G. Plantas infestantes e nocivas - Plantas inferiores: monocotiledôneas. 2.ed. São Paulo: BASF, 1997. Tomo I. $825 \mathrm{p}$.

KUVA, M. A. et al. Períodos de interferência das plantas daninhas na cultura da cana-de-açúcar. III - capim-braquiária (Brachiaria decumbens) e capim-colonião (Panicum maximum). Planta Daninha, v. 21, n. 1, p. 37-44, 2003

KUVA, M. A. et al. Plantas daninhas emergentes em canaviais. Idea News, p. 94-98, 01 ago. 2008.

KUVA, M. A. Banco de sementes, fluxo de emergência e fitossociologia de comunidade de plantas daninhas em agroecossistema de cana crua. 2006. 105 f. Tese (Doutorado em Produção Vegetal) - Universidade Estadual Paulista, Jaboticabal, 2006.

KUVA, M. A. et al. Períodos de interferência das plantas daninhas na cultura da cana-de-açúcar. II - Capim-braquiária (Brachiaria decumbens). Planta Daninha, v. 19, n. 3, p. 323-330, 2001.
KUVA, M. A. et al. Períodos de interferência das plantas daninhas na cultura da cana-de-açúcar. I - Tiririca. Planta Daninha, v. 18, n. 2, p. 241-251, 2000

KUVA, M. A. et al. Fitossociologia de comunidades de plantas daninhas em agroecossistema cana-crua.

Planta Daninha, v. 25, n. 3, p. 501-511, 2007.

MARTINS, D. et al. Emergência em campo de dicotiledôneas infestantes em solo coberto com palha de cana-de-açúcar.

Planta Daninha, v. 17, n. 1, p. 151-161, 1999.

MEIRELLES, G. L. S. et al. Determinação dos períodos de convivência da cana-soca com planta daninhas.

Planta Daninha, v. 27, n. 1, p. 67-73, 2009.

MONQUERO, P.A. et. al. Eficácia de herbicidas em diferentes quantidades de palha de cana-de-açúcar no controle de Euphorbia heterophylla. Planta Daninha, v. 25, n. 2, p. 613-619, 2007.

MUELLER-DOMBOIS, D.; ELLEMBERG, H. Aims and methods of vegetation ecology. New York: John Wiley \& Sons, 1974. 547 p.

PITELLI, R. A. Interferência de plantas daninhas em culturas agrícolas. Inf. Agropec., v. 11, n. 129, p. 16-27, 1985.

PITELLI, R. L. C. M. et al. Utilização de análise multivariada e redes neurais artificiais na determinação do comportamento de colonização de populações de macrófitas aquáticas no reservatório Santana. Planta Daninha, v. 27, n. 3, p. 429-439, 2009.

ROLIM, J. C.; PASTRE, W. Eficiência agronômica de smetolachlor na cultura da cana-de-açúcar. In: CONGRESSO BRASILEIRO DA CIÊNCIA DAS PLANTAS DANINHAS, 22., 2000, Foz do Iguaçu. Resumos... Foz do Iguaçu: 2000. p. 310 .

SALVADOR, F. L. et al. Efeito da luz e da quebra de dormência na germinação de espécies de plantas daninhas. Planta Daninha, v. 25, n. 2, p. 303-308, 2007.

SILVA, I. A. B. et al. Interferência de uma comunidade de plantas daninhas com predominância de Ipomoea hederifolia na cana-soca. Planta Daninha, v. 27, n. 2, p. 265-272, 2009.

TABACHNICK, B. G; FIDELL, L. S. Using multivariate statistics. California: Harper \& Row, 1983. 445 p. 